\title{
Transição para o ensino secundário: vozes de estudantes em dois sistemas educativos
}

\section{Transition to upper secondary education: student voices in two education}

\author{
systems \\ Ana Cristina Torres* \\ * Centro de Investigação e Intervenção Educativas, Faculdade de Psicologia e Ciências da Educação da Universidade do Porto
}

\begin{abstract}
Resumo
Apresentam-se e comparam-se vozes de estudantes de dois sistemas educativos - Portugal e Escócia - sobre a sua transição para o ensino secundário, enquadrando-se esta problemática no campo do desenvolvimento curricular. A recolha recorreu a grupos de discussão focalizada que exploraram os fatores de escolha do curso e/ou disciplinas e escola que os e as estudantes estavam a frequentar, e sobre as principais dificuldades experienciadas na transição. Conclui-se confrontando e problematizando opostos de obrigatoriedade, flexibilidade e escolha que subjazem ao ensino secundário nestes dois sistemas educativos com base nas vozes auscultadas.

Palavras chave: Transição; Ensino Secundário; Vozes de estudantes; Escolhas; Dificuldades;
\end{abstract}

\begin{abstract}
Student voices about the transition to upper secondary education in two education systems - Portugal and Scotland - are presented and compared, framing this problematic in the field of curriculum development. Data collection comprised focus groups in which aspects of course and subject choice were explored as well as the main difficulties experienced in the transition. The conclusion confronts and problematizes the opposites of compulsory, flexibility and choice underlying upper secondary education in these two education systems based on the listened voices

Keywords: Transition; Upper secondary education; Student voices; Choices; Difficulties;
\end{abstract}

A entrada no ensino secundário, ou níveis equivalentes, é sempre um período importante no percurso de vida dos e das jovens. Estes vêm-se obrigados a efetuarem escolhas que configuram as suas expectativas académicas e profissionais, por vezes, de uma forma desfasada das suas temporalidades de desenvolvimento individual (Vieira, Pappámikail \& Nunes, 2012). Em Portugal, essas escolhas ganham contornos ainda mais complexos devido à matriz curricular rígida e excessivamente afunilada do ensino secundário. Já na Escócia, um novo currículo, atualmente em introdução neste ciclo de escolaridade, incorpora princípios de flexibilidade, personalização e escolha (Education Scotland, 2016), os quais têm gerado diversas dificuldades na sua implementação, não só por parte das escolas e professores, como de estudantes, ao terem de gerir um leque diversificado de escolhas que nem sempre é claro nas possibilidades de destinos aos quais os podem levar. Como resultado, surgem problemas de agravamento do insucesso e desafetação escolares no início deste ciclo de escolaridade os quais, por vezes, resultam em inflexões nos percursos escolares, frustrações académicas e sociais e no limite, como destacou o recente relatório da OCDE (2017), para o caso de Portugal, abandono escolar precoce.

Como tal, apresentam-se e descrevem-se brevemente as comunalidades e diferenças que estudantes de Portugal e Escócia referiram experienciar no início do ensino secundário, com foco no modo referiram fazer as suas escolhas de cursos e/ou disciplinas, e nas dificuldades que referiram sentir à entrada do ensino secundário, discutindo as relações entre as perspetivas apresentadas pelos jovens nos grupos de discussão e as organizações curriculares tão distintas nos dois sistemas educativos.

\section{Transição de estudantes para o ensino secundário}

As transições entre ciclos de escolaridade são etapas permeadas por alguma incerteza e instabilidade, tendo vindo a receber, por isso, atenção de diversos campos de investigação e das políticas educativas. Iniciativas são levadas a cabo por escolas, comunidades e autoridades locais, regionais ou nacionais para facilitar a transição de estudantes entre etapas da escolaridade, particularmente quando as mesmas envolvem mudança de escola. E enquanto algumas transições são perturbadoras e difíceis para alguns, para outros, o risco, o desafio e a dificuldade podem mesmo estimular uma transição de sucesso (Ecclestone, Biesta, \& Hughes, 2010). A atenção à transição para o ensino secundário em Portugal, ainda é escassa (Torres \& Mouraz, 2015), pese embora os persistentes níveis de insucesso no $10^{\circ}$ ano (GIASE, 2006; Fernandes, 2006) e frequente crescimento da desafetação escolar ao longo desta etapa (Araújo et al, 2014). Constitui-se uma etapa na qual os alunos se vêm subitamente mais responsabilizados pelo seu próprio projeto de vida decorrente da opção de curso que assumem à entrada do ensino secundário (Matos, 2013), 
e pelo facto de deles ser frequentemente exigida uma maior autonomia e mais trabalho académico que na educação básica (Torres \& Mouraz, 2015). Adicionalmente, a possibilidade de mudança de escola ou, simplesmente, de turma, pode arrastar consigo a alteração das redes de amigos, colegas e professores e de relações interpessoais, numa etapa de desenvolvimento individual onde as mesmas se revestem de especial importância, arriscando-se uma "desestruturação identitária e social” (Abrantes, 2005). Nesta problemática, é de especial importância, o apoio emocional de colegas, pares e docentes (De Wit et al., 2010).

\section{Vozes de estudantes sobre o currículo}

Ouvir o que estudantes têm a dizer sobre o currículo do ensino secundário justifica-se por duas ordens de razões. Ao nível do desenvolvimento curricular, constitui-se um modo de tornar os currículos mais contextualizados, motivadores e próximos das realidades dos/das estudantes. E ao nível do desenvolvimento individual e educativo dos e das estudantes, constitui-se uma forma de empoderamento e responsabilização destes em matéria da sua própria aprendizagem (Ngussa \& Makewa, 2014), enquanto se aumenta o seu envolvimento e agência na vida da escola (Biddulph, 2011; Brasof, 2015). Ainda no que concerne o desenvolvimento curricular, interessa aprofundar, do ponto de vista de quem experiencia a transição (estudantes de $10^{\circ}$ ano), o fosso histórico persistente entre as exigências curriculares do ensino básico e aquelas do ensino secundário (Garrido, 1999), como forma de melhor sustentar reformas curriculares como a do atual projeto em curso de autonomia e flexibilização curricular.

\section{Portugal e Escócia: contrastes nos princípios de organização e gestão curricular}

Ao ensino secundário português, corresponde a senior phase escocesa, sendo que em ambas, os estudantes entram com aproximadamente 15 anos de idade. Portugal e Escócia possuem, de facto, elevados contrastes nas configurações dos seus sistemas educativos e, como consequência, em princípios de organização e gestão curricular que lhes subjazem. À cabeça, e uma das motivações para o estudo nestes dois contextos, constituise a extensão da escolaridade obrigatória quem Portugal passou recentemente a 12 anos de escolaridade, enquanto na Escócia, mantém-se nos 10 anos de escolaridade. A lógica escocesa é a de que os e as estudantes saiam da escolaridade obrigatória com alguma certificação de competências, a qual ocorre com a especialização disciplinar e examinação no final do nível S4, o correspondente ao $10^{\circ}$ ano de escolaridade português. De facto, enquanto os alunos portugueses já passaram durante o seu percurso de educação básica por avaliações externas, os alunos escoceses apenas entram nesta realidade no final deste nível de escolaridade (S4). Uma outra diferença, que permeia até o conceito de nível de escolaridade, reside no princípio de progressão. De facto, enquanto em Portugal a progressão de nível de escolaridade corresponde à progressão de ano de escolaridade, tal correspondência não ocorre no sistema escocês, porquanto num mesmo ano de escolaridade, podem ser encontrados alunos com qualificações em diferentes níveis. A flexibilidade dos percursos escolares no ensino secundário é também muito distinta nestes dois sistemas educativos. Em Portugal, os planos de estudos constituem-se historicamente planos pré-definidos de 3 anos de estudos com finalidades específicas - a tradicional dicotomia entre preparação para o ensino superior e preparação para o mercado de trabalho. Já na Escócia, os alunos podem frequentar, por ano de escolaridade, um total de 6 a 8 disciplinas de acordo com o currículo previsto e a oferta de escola ou de parcerias locais de escolas com outras instituições (colleges, empresas, associações comunitárias, entre outras). Neste leque, e no que concerne especificamente o nível S4, é obrigatória a inclusão do Inglês (língua materna), da Matemática e da Educação Física, podendo as restantes disciplinas escolhidas pelos alunos. Assim, enquanto em Portugal, à entrada do ensino secundário, os alunos são obrigados a entrar numa única rota de aprendizagem delineada pelo curso escolhido, podendo apenas reorientar essa rota entre cursos com afinidade de planos de estudos, na Escócia, à entrada da senior phase, os alunos podem integrar múltiplas rotas de aprendizagem de acordo com a articulação de princípios de personalização e escolha previstos no currículo com a oferta formativa e as metas pessoais dos alunos. Será ainda de se destacar alguns aspetos da avaliação interna dos alunos. Enquanto em Portugal, a avaliação interna é principalmente classificativa ( 0 a 20 ), ainda que no ensino profissional, recorrendo ao sistema modular, na Escócia, todo o sistema de ensino na senior phase, seja em disciplinas mais académicas, seja em disciplinas mais vocacionais, é um sistema modular, sendo que no final de cada unidade de ensino, os alunos apenas são avaliados como pass/fail. Apenas no final do nível do S4, onde estes alunos iniciam as suas avaliações externas para obtenção de qualificações, podem ser classificados em 5 níveis (A a D ou No award).

\section{Abordagem metodológica}

Objetivos. O estudo aqui apresentado procurou (1) identificar dificuldades que os e as estudantes experienciam à entrada do ensino secundário, com foco nas dificuldades académicas; e (2) comparar a experiência de transição de estudantes em diferentes cursos, organizações curriculares e organizações escolares.

Recolha de dados. A recolha de dados foi efetuada em Portugal e na Escócia. Em Portugal realizaram-se 6 grupos de discussão focalizada com estudantes do $10^{\circ}$ ano de escolaridade em 2 escolas secundárias e 2 escolas profissionais. Na Escócia, realizaram-se 8 grupos de discussão focalizada em 6 high school e 1 further education college. Em cada grupo de discussão participaram entre 6 a 8 estudantes, sendo que, quer para o caso português, quer para o caso escocês, se procurou separar grupos onde os estudantes estavam a frequentar percursos principalmente académicos de grupos onde os 
estudantes estavam a frequentar percursos profissionais/vocacionais.

Análise de dados. As perspetivas recolhidas nos grupos de discussão foram sujeitas a uma análise de conteúdo (Bardin, 2000) de natureza exploratória e interpretativa, utilizando o software NVivo®.

Participantes. Nos grupos de discussão em Portugal participaram um total de 32 estudantes do $10^{\circ}$ ano de escolaridade, dos quais 20 frequentavam cursos profissionais e 12 frequentavam cursos científicohumanísticos, 15 eram raparigas e 17 eram rapazes, e à exceção de 3 , todos estavam pelo primeiro ano nas escolas que frequentavam. Já na Escócia, participaram 29 estudantes do nível S4 em percursos exclusivamente académicos e 21 em percursos com um misto de disciplinas académicas e vocacionais, em que 15 eram raparigas e 35 rapazes. No caso das high school, apenas uma aluna tinha mudado de escola nesse ano. No caso da further education college, todos estavam a frequentar esta instituição pela primeira vez, ainda que apenas uma vez por semana.

\section{Resultados: escolhas e dificuldades à entrada do ensino secundário / senior phase}

Em jeito de preâmbulo da apresentação das dificuldades experienciadas por estes estudantes à entrada do ensino secundário / senior phase, percebeu-se ser essencial explorar um pouco dos modos como estes estudantes escolheram os seus cursos e/ou disciplinas, porquanto tais escolhas condicionam as vivências durante a transição e a confirmação, ou não, de expectativas criadas.

Escolha de escola e de cursos/disciplinas. Em Portugal, os discursos dos estudantes nos grupos de discussão revelaram que a escolha do curso surge fortemente associada à escolha da escola. É muito comum a mudança de escola nesta transição, pelo que, vários dos estudantes participantes mencionaram a conjugação da localização e da oferta das escolas secundárias mais próximas, com os seus ambientes percecionados, ou com a possibilidade de manter a proximidade de amigos, como fatores de escolha de escola e, por consequência, de curso. Quase todos os estudantes de cursos científico-humanísticos, e alguns de cursos profissionais em escolas secundárias, tinham ido para a sua escola atual por ser a mais perto da sua antiga escola, ou porque os seus amigos tinham ido para lá. Em seguida, escolhiam o curso pelo seu gosto pela área e/ou algumas disciplinas do curso, ou por ser a via de acesso ao curso de ensino superior que tinham em mente. Algumas referências, ainda que escassas, faziam notar a escolha de um determinado curso por medo de falhar noutro curso (ou em algumas disciplinas) que poderia ser o preferido. Já no que concerne estudantes de cursos profissionais, a maioria dos participantes dos grupos em escolas profissionais e na escola secundária de contexto urbano, tinham efetivamente ido para aquelas escolas, primeiramente, pela oferta específica do curso que estavam a frequentar. Em alguns casos até, tal implicava longas deslocações diárias, ou mesmo regime de internato. A orientação vocacional no final da educação básica foi mencionada mais como forma de confirmação de escolhas já efetuadas, ou de esclarecimento de dúvidas acerca das ofertas formativas, do que propriamente como fator preponderante nas escolhas.

O caso escocês revelou menores complexidades, logo à cabeça, pelo facto de ser rara a mudança de escola nesta transição. Apenas uma aluna mencionou ter mudado de escola porque na sua escola anterior apenas podia escolher 6 disciplinas, enquanto na sua escola atual podia escolher 8 disciplinas, o que era visto como uma vantagem para alargar o seu leque de oportunidades futuras. Assim, nos casos de estudantes que estavam a frequentar apenas disciplinas académicas, a esmagadora maioria referiu estar a frequentar as disciplinas que acharam mais interessantes, dentro da oferta formativa da escola, ou aquelas nas quais jugavam poder conseguir melhores desempenhos. Quando a escola, através de parcerias com further education colleges, permitia que dentro desse leque se integrassem disciplinas de cariz vocacional, aqueles estudantes que as escolheram, mencionaram tê-lo feito por estarem à procura de disciplinas mais práticas. Alguns estudantes admitiram que $o$ facto de julgarem umas disciplinas mais interessantes que outras teria a ver com a orientação e/ou influência de familiares, ou com experiências passadas positivas com determinados professores.

Dificuldades experienciadas na transição. A principal dificuldade mencionada por estudantes portugueses em cursos científico-humanísticos consistiu na perceção de um aumento brusco do ritmo de ensino dos conteúdos e da consequente pressão sentida para o cumprimento dos programas. De modo semelhante, os estudantes escoceses que se encontravam a frequentar apenas disciplinas académicas, referiram também como principal dificuldade experienciada, o ritmo de ensino dos conteúdos e o aumento da pressão que era exercida neles, mas, desta feita, para o cumprimento de prazos de entrega de trabalhos que eram utilizados na sua avaliação às unidades de ensino.

«as stôras estão sempre a pressionar, dizendo que há muita matéria e que temos de estudar» (Lucas)

«a pressão que é feita nos alunos (...) que é, temos que ver isto agora, e tudo muito rápido» (Alice)

«temos que perceber a matéria no próprio dia. Se não percebemos a matéria do dia anterior, já não percebemos nada para a frente» (Sara)

«the pace of the coursework is faster» (Allan)

«teachers have been rushing the courses contents

in the past few months for the exams» (Corey)

«more academic subjects can be stressful due to

the assignment deadlines often in place» (Heather)

De modo transversal a estudantes de percursos académicos dos dois países, a necessidade, aparentemente súbita, de desenvolveram mais autonomia, mais empenho e maior resiliência, pode ser 
deslindada nos seus discursos como uma dificuldade experienciada que, se para uns e tornou um desafio a superar, para outros foi mais perturbadora.

«no ano passado, o meu estudo era conforme o meu gosto pela disciplina e, este ano, eu sei que não pode ser assim. (...) agora aplico-me o dobro, numa disciplina que sei que não gosto» (Edgar)

«algum estudo por fora, até porque os próprios exercícios nos obrigam a termos de estudar antes» (Alice)

«eu, basicamente, agora, estou atento, e mesmo assim, se não perceber as coisas à primeira, tento estar ainda mais atento e colocar questões» (Elias) «although harder, being in the subjects you really want improves your attitude towards school and study» (Eddie)

«homework increased and is difficult to balance the homework with my other activities» (Zara)

Já estudantes portugueses em cursos profissionais mencionaram, quase de forma unânime, o aumento da carga horária e a sua distribuição como a principal dificuldade experienciada à entrada do ensino secundário, por vezes exacerbada pelo facto de terem que fazer deslocações longas diárias ou terem de ficar em regime de internato.

«Nós temos aulas a semana toda das $8 h$ às $18 h$. E temos aulas que não precisávamos de ter tantas vezes, e aulas que temos poucas e precisávamos de ter mais» (Adriana)

Uma outra dificuldade mencionada por estes estudantes, encontrou equivalência nas vozes de estudantes escoceses que frequentavam um misto de disciplinas académicas com disciplinas vocacionais. Era esta a perceção de diferentes estilos de ensino dos professores. Enquanto para os estudantes portugueses, era a compreensão de que alguns professores integravam o modelo pedagógico modular do ensino profissional com um ritmo mais característico do ensino académico...

«alguns professores ainda estão agarrados aos hábitos do ensino regular (...), e mesmo o ritmo da aula vai de maneira diferente» (Andreia)

... para estudantes escoceses, era as elevadas diferenças entre os ritmos de ensino em disciplinas académicas e em disciplinas vocacionais.

"college courses (vocational) are more relaxed whereas at school (academic) they are pushing and pushing you» (Alison)

\section{Considerações finais}

A entrada no ensino secundário, a nível internacional, parece continuar a ser o primeiro grande embate com a "cultura" da examinação e da acumulação de conteúdos para o ensino superior, o que emerge neste estudo das vozes de estudantes em percursos mais académicos. Adicionalmente, a elevada rigidez dos planos de estudos em Portugal, parece comprometer um princípio básico de escolha do percurso e oportunidades futuras dos jovens, quando atualmente precisam de estar num determinado percurso escolar, à luz da escolaridade obrigatória. Por oposição, num sistema educativo onde a escolaridade obrigatória é mais reduzida, paradoxalmente, mais possibilidades de escolha de tipo de percurso escolar são dadas aos jovens. Os discursos destes jovens fazem emergir a necessidade de maior flexibilidade curricular no ensino secundário português, a qual deve incluir maior flexibilidade nos planos de estudos (dentro de limites, para os quais o exemplo escocês pode ser um bom exemplo) para facilitar a adaptação de estudantes ao ensino secundário e melhorar o seu envolvimento nas suas próprias aprendizagens. Pode também resolver algumas limitações colocadas aos estudantes em termos da oferta formativa das escolas.

\section{Referências}

Abrantes, P. (2005). As transições entre ciclos de ensino: entre problema social e objecto sociológico, Interacções, 1, 25-53.

Araújo, H. C., Magalhães, A. M., Rocha, C., \& Macedo, E. (2014). Policies on Early School Leaving in Nine European Countries: A Comparative Analysis. Antwerp: University of Antwerp.

Bardin, L. (2000). Análise de conteúdo. Lisboa: Edições 70 ( $1^{a}$ edição de 1977).

Biddulph, M. (2011). Articulating student voice and facilitating curriculum agency. The Curriculum Journal, 22(3), 381-399. doi:10.1080/09585176.2011.601669

Brasof, M. (2015). Student Voice and School Governance: Distributing Leadership to Youth and Adults. New York, Routledge.

De Wit, D. J., Karioja, K., \& Rye, B. J. (2010) Student perceptions of diminished teacher and classmate support following the transition to high school: are they related to declining attendance?, School Effectiveness and School Improvement: An International Journal of Research, Policy and Practice, 21 (4), 451-472, DOI: 10.1080/09243453.2010.532010

Ecclestone, K., Biesta, G., \& Hughes, M. (2010). Transitions in the lifecourse - The role of identity, agency and structure. In K. Ecclestone, G. Biesta, \& M. Hughes (Eds.), Transitions and Learning Through the Lifecourse (pp. 1-15). Oxon: Routledge.

Education Scotland (2016). Progression from the Broad General Education (BGE) to the Senior Phase: updated guidance. Livingston: Education Scotland. http://www.educationscotland.gov.uk/resources/c/gen ericresource_tcm4748089.asp

Fernandes, D. (2006). Revisitando a revisão curricular (1997-2001): Um contributo para pensar o futuro do ensino secundário. Educação. Temas e Problemas, 2, 129-158. 
Garrido, J. L. (1999). Problemas do ensino secundário superior. In: J. Azevedo (Ed.), O Ensino Secundário em Portugal (pp. 229-236). Lisboa: Conselho Nacional de Educação.

GIASE (2006), Séries Cronológicas: 30 Anos de Estatísticas da Educação, 2 volumes, Lisboa, GIASEME.

Matos, M. (2013). O ensino secundário entre a "tentação neoliberal e a razão comunitária" in Matos, $\mathrm{M}$. (Coord.) com a colaboração de Caramelo, J., JOVALES, Jovens, Alunos, Ensino Secundário (pp. 37-50). Porto: CIIE/FPCEUP e Livpsic.

Ngussa, B. M. \& L. N. Makewa (2014). Student Voice in Curriculum Change: A Theoretical Reasoning. International Journal of Academic Research in Progressive Education and Development, 3 (3, Special Issue), 23-37. DOI: 10.6007/IJARPED/v3-i3/949

OECD. (2017). Portugal - Country Note. In OECD (Ed.), Education at a Glance 2017: OECD Indicators. Paris: OECD Publishing. http://dx.doi.org/10.1787/eag2017-64-en

Torres, A. C., Mouraz, A. (2015). Students' transition experience in the 10th year of schooling: perceptions that contribute to improving the quality of schools. Improving Schools, 18 (2), 127-141. doi: 10.1177/1365480215581460

Vieira, M. M., Pappámikail, L., \& Nunes, C. (2012). Escolhas escolares e modalidades de sucesso no ensino secundário: percursos e temporalidades. Sociologia, problemas e práticas, 70, 45-70. http://dx.doi.org/10.7458/SPP2012701210

\section{Agradecimentos}

Financiamento da Fundação para a Ciência e a Tecnologia (SFRH/BPD/108950/2015) no âmbito do Programa Operacional Capital Humano, comparticipado pelo Fundo Social Europeu e por fundos nacionais do MCTES 